Vol.60: e17160352, January-December 2017 http://dx.doi.org/10.1590/1678-4324-2017160352 ISSN 1678-4324 Online Edition
BRAZILIAN ARCHIVES OF

BIOLOGY AND TECHNOLOGY

AN INTERNATIONAL JOURNAL

\title{
Molecular Characterization of a MYB Protein from Oryza sativa for its Role in Abiotic Stress Tolerance
}

\author{
Farah Deeba $^{1}$, Tasawar Sultana ${ }^{1}$, Bushra Javaid ${ }^{1}$, Tariq Mahmood ${ }^{2}$, S. M. S. Naqvi ${ }^{{ }^{*}}$. \\ ${ }^{1}$ Department of Biochemistry, PMAS Arid Agriculture University Rawalpindi, Rawalpindi, Pakistan; ${ }^{2}$ Department of \\ Plant Sciences, Quaid e Azam University, Islamabad, Pakistan
}

\begin{abstract}
The MYB family represents one of the most abundant classes of transcriptional regulators that perform pivotal role under different developmental processes and abiotic stresses. In present study, a MYB gene from Oryza sativa was selected for functional characterization. Bioinformatics analysis revealed that OSMYB1 cDNA encodes R2-R3 type DNA binding domain consisting of 413 amino acids having size of $44 \mathrm{kDa}$ and pI of 6.24. DNA binding domain containing region was cloned and over-expressed in E. coli. Then, the survival of pGEX-OsMYB1 transformed E. coli cells was compared with control plasmid under different concentrations of $\mathrm{NaCl}$, mannitol, high and low temperature. $p G E X-O S M Y B 1$ enhanced the survival of cells at high temperature and salinity. Electrophoretic mobility shift assays (EMSAs) have shown that recombinant OsMYB1 protein was able to bind with DIG labeled probe containing MYB binding site. RT-qPCR analysis revealed high MYB1 expression under wounding, salt, drought and heat stresses in rice. Expression was 23 fold higher in response to wounding demonstrating the worth of OSMYB1 up-regulation in wounding. Intrinsic disorder profile predicted that OsMYB1 exhibits $60 \%$ degree of intrinsic disorder proposing that these regions might be involved in DNA binding specificity and protein-protein interaction. The positive response of OsMYB1 suggests that its over-expression in crop plants may help in providing protection to plants to grow under abiotic stresses.
\end{abstract}

Keywords: abiotic stress, E. coli, Oryza sativa, OsMYB1, pGEX, Real time qPCR

\footnotetext{
*Author for correspondence: saqlan@uaar.edu.pk
} 


\section{INTRODUCTION}

Various environmental factors have negative impact on plant growth, development and productivity including salinity, high and low temperature, water logging, wounding and mineral deficiencies. Plants survive these abiotic stresses by unleashing sophisticated survival approaches involving initiation of stress specific adaptive responses to overcome the adverse effects of these stresses ${ }^{1}$. Expression of several genes is initiated by different stresses which may be divided into two classes, i.e. functional and regulatory genes. The regulatory genes are mostly comprised of transcription factors, grouped into different families such as bZIP, DREB, DOF, MYC/MYB, NAC and WRKY. These transcription factors manage the expression of numerous downstream genes involved in providing stress tolerance to plants. High throughput technologies have provided considerable insight in deciphering the molecular approaches of abiotic stress tolerance linking a number of functional and regulatory genes. In addition to regulatory cis-elements in plant promoters and transcription factors, information about several stress responsive genes have been gathered $^{2}$.

The MYB transcription factors encompass one of the major class in the plant domain. MYB transcription factors are composed of 2 distinct regions, a conserve MYB DNA binding domain at the N-terminus and a varied modulator region at the $\mathrm{C}$-terminus which is involved in controlling regulatory activities of proteins. Based on number of domains, MYB proteins can be distributed into different groups, out of which R2-R3 MYB proteins are specific and most copious type in plants having more than 100 members in higher plants including Arabidopsis and rice ${ }^{3}$. It is named as MYB because the first gene of MYB domain protein was isolated from avian myeloblastosis virus ${ }^{4}$. Afterwards, numerous MYB genes were documented in animals, plants and fungi ${ }^{5}$. The MYB proteins in plants are conserved both in structure and function in comparison to animals and yeasts.

The plant MYB transcription factors have been documented to contribute in several phases of plant growth and development, for instance, the regulation of primary and secondary metabolism, the control of cell cycle and response to abiotic and biotic stresses $^{6,7}$. The expression profiles of numerous MYB genes were investigated for their role in responding to phytohormones and stress conditions in higher plants. For instance, AtMYB13, AtMYB15, AtMYB33, AtMYB102 and AtMYB96 are implicated in responding to wounding, salinity, ABA signaling and osmotic stresses $^{8,9}$. In rice, OsMYB55 is a key regulatory component in response to high temperature ${ }^{10}$ and $O s \mathrm{MYB} 2$ is involved in responding to salt, cold and drought stresses ${ }^{11}$.These annotations proposed the participation of MYB proteins under abiotic stresses and hormonal changes. Nevertheless, little is known about the role of rice MYB proteins in abiotic stresses.

Availability of comprehensive knowledge about MYB proteins will allow modifying them in beneficial ways in the current situation of increasing global warming. Present study was carried out to decipher the role of MYB1 protein from rice in abiotic stresses. Different properties of $O s \mathrm{MYB} 1$ were analyzed using various bioinformatics tools. DNA binding domain containing region was cloned and functionally characterized by analyzing its response in $E$. coli under different abiotic stresses. OsMYB1 gene expression level was also monitored by real time qPCR in rice in response to cold, salt, drought, heat and wounding/mechanical stress. 


\section{MATERIAL AND METHODS}

\section{Bioinformatics Analysis}

The NCBI database was used for searching OsMYB1 nucleotide and protein sequences and CLUSTALW for sequence alignment. SMART (http://smart.emblheidelberg.de/) online tool was used to predict conserve DNA binding domain. Secondary structure was predicted by PSIPRED Protein Structure Prediction server (http://bioinf.cs.ucl.ac.uk/psipred/). Nuclear localization signals (NLS) prediction was carried out using online tool WoLF pSORT (http://www.genscript.com/wolfpsort.html). Primary sequence was analyzed by DISOPRED (http://bioinf.cs.ucl.ac.uk/psipred/?disopred=1) to measure the degree of intrinsic disorder. Protein-protein interaction network was constructed by STRING (http://string-

db.org/newstring_cgi/show_input_page.pl?UserId=TwZ3I284aTRf\&sessionId=AzW VpTDVECpt). The interactions comprise of physical and functional combinations.

\section{Plant Material and Growth Conditions}

Seeds of Oryza sativa cv. KS282 obtained from Rice Program, Crop Science Institute, National Agricultural Research Centre (NARC) Islamabad were germinated on half strength MS medium and kept at $25^{\circ} \mathrm{C}$ in growth room for ten days. Total RNA was isolated using RNA extraction kit (Qiagen) and subjected to cDNA synthesis.

\section{Stress Treatments and RT-qPCR}

Gene expression database, Genevestigator (Plant Biology) (https://genevestigator.com/gv/plant.jsp), was searched out to find the microarray data for OsMYB1 (Os01g0850400) and up-regulation of OsMYB1 gene was observed in various stresses. The data acquired was for abiotic stresses including cold, heat, drought and salt stresses.

Oryza sativa $c v$. KS282 seeds were grown on MS medium at $25^{\circ} \mathrm{C}$ for 10 days. Ten day old rice seedlings were subjected to different abiotic stresses. For drought treatment, plants were placed on aluminium foil till visible leaf rolling appeared in the plants. Cold treatments were performed by transferring 10 day old seedlings to $4^{\circ} \mathrm{C}$ with a $12 \mathrm{~h} \mathrm{light} / 12 \mathrm{~h}$ dark photoperiod. After $48 \mathrm{~h}$ of cold treatment, seedlings were moved to $25^{\circ} \mathrm{C}$ and samples were collected after $24 \mathrm{~h}$ following recovery from cold stress. High salt stress was carried out by immersing the plant roots in a beaker containing $200 \mathrm{mM} \mathrm{NaCl}$ solution for $3 \mathrm{~h}$ at $28 \pm 1{ }^{\circ} \mathrm{C}$. Seedlings were subjected to $45^{\circ} \mathrm{C}$ for $6 \mathrm{~h}$ for heat stress. For wounding, seedlings were cut into pieces $7 \mathrm{~mm}$ in length and then left in water at room temperature under continuous light for $6 \mathrm{~h}$. Samples were collected separately and kept at $-80^{\circ} \mathrm{C}$ until analysis. RNA was isolated from different stressed and control plants using the RNeasy Plant Mini Kit (Qiagen). Primers were designed for actin and OsMYB1 (Supplementary table 1) and Quantitative real time PCR was performed using Brilliant II SYBR Green QRTPCR Master Mix Kit (Agilent Technologies). Samples were assessed in a $10 \mu \mathrm{L}$ reaction mixture containing $5 \mu \mathrm{L}$ of $2 \times$ reaction mix, $100 \mathrm{ng}$ of each forward and reverse primers, $100 \mathrm{ng}$ of RNA, $0.1 \mu \mathrm{L}$ of reverse transcriptase and $1.8 \mu \mathrm{L}$ of nuclease free water. Control reactions having no primer and no template were also included. The RT-qPCR profile consists of one cycle for reverse transcription at $50^{\circ} \mathrm{C}$ for $30 \mathrm{~min}$ and polymerase activation at $95^{\circ} \mathrm{C}$ for $10 \mathrm{~min}$, followed by 40 cycles of PCR at $95^{\circ} \mathrm{C}$ for $30 \mathrm{~s}, 53^{\circ} \mathrm{C}$ for $1 \mathrm{~min}$ and $72^{\circ} \mathrm{C}$ for $30 \mathrm{~s}$. The $2^{-\Delta \Delta \mathrm{CT}}$ method was employed to compute the relative change in transcript levels with actin as 
internal standard to determine relative expression levels. RT-qPCR assays were repeated at least twice and each repetition had three replicates.

Cloning and Expression in E. coli

DNA binding domain containing region of OsMYB1 was PCR amplified using Forward 5'-CGCGGATCCATGGATGACGTCGTCATC-3' and Reverse 5'CCGCTCGAGTCAACCACCTTGTGTGCA-3' using cDNA as template. Underlined regions are restriction sites for BamHI and XhoI respectively. PCR was carried out in $20 \mu \mathrm{L}$ reaction mix containing $4 \mu \mathrm{L}$ of $5 \mathrm{x}$ HF Phusion buffer, $0.4 \mu \mathrm{L}$ $10 \mathrm{mM}$ dNTPs, $10.8 \mu \mathrm{L}$ water (nano pure), $1 \mu \mathrm{L}$ of each primer $(10 \mu \mathrm{M}), 0.2 \mu \mathrm{L}$ of Phusion DNA polymerase, $0.6 \mu \mathrm{L}$ DMSO and $100 \mathrm{ng}$ of cDNA. PCR cycle conditions included heating the PCR reaction for pre-denaturation at $95^{\circ} \mathrm{C}$ for $1 \mathrm{~min}$, followed by 35 cycles of denaturation at $95^{\circ} \mathrm{C}$ for $20 \mathrm{sec}$, annealing at $65^{\circ} \mathrm{C}$ for 20 sec and extension at $72^{\circ} \mathrm{C}$ for $20 \mathrm{sec}$. A final extension was given at $72^{\circ} \mathrm{C}$ for 10 min. The amplicon with BamH1 and XhoI sites was subcloned into pGEX4T-1 vector and transformed in the E. coli BL21 strain to generate the putative pGEXOsMYB1 (Supplementary Figure 1). The desired recombinant plasmids were identified by PCR amplification, restriction digestion and commercial sequencing. The prokaryotic expression product was induced with $1.0 \mathrm{mM}$ isopropyl b-Dthiogalactoside (IPTG) for $6 \mathrm{~h}$ at $37^{\circ} \mathrm{C}$ and analyzed by sodium dodecyl sulfatepolyacrylamide gel electrophoresis (SDS-PAGE).

\section{Electrophoretic mobility shift assay (EMSA)}

Oligonucleotides (30 bp) containing MYB binding site (WAACCA) were annealed by heating at $95^{\circ} \mathrm{C}$ for $10 \mathrm{~min}$ and then slowly cooled to room temperature in TEN buffer (Tris $(10 \mathrm{mM}, \mathrm{pH}), 1 \mathrm{mM}$ EDTA $100 \mathrm{mM} \mathrm{NaCl})$. A DIG Gel Shift kit (Roche) was used to detect DNA-protein interaction. Digoxigenin (DIG) was labeled at the $3^{\prime}$ end of the double-stranded oligonucleotides. The labelled probes were then purified by ethanol precipitation. The pellet was air dried and resuspended in $\mathrm{ddH}_{2} \mathrm{O}$ to a final concentration of $2.5 \mathrm{pmol} / \mu \mathrm{L}$. Labelling efficiency was tested by spotting serial dilutions on nylon membrane along with control labelled oligonucleotides provided with the kit. DIG labeled $(50 \mathrm{fmol})$ and unlabeled $(10 \mathrm{pmol})$ oligonucleotides were mixed with GST-OsMYB1 $(1 \mu \mathrm{g})$ in binding buffer and incubated at room temperature for $30 \mathrm{~min}$. The reaction products were fractionated through a pre-run $6 \%$ non-denaturing polyacrylamide gel for $90 \mathrm{~min}$ in $0.5 \mathrm{X} \mathrm{TBE}$ buffer at $4{ }^{\circ} \mathrm{C}$, then electrophoretically transferred to a positively charged nylon membrane (Roche) by applying a constant current of $300 \mathrm{~mA}$ for $30 \mathrm{~min}$. The DNA was cross-linked to the membrane using a UV stratalinker (Stratagene). The nylon membrane was blocked in $1 \mathrm{X}$ blocking reagent for $1 \mathrm{~h}$ at room temperature and then incubated with a 1:20,000 dilution of anti-DIG antibody coupled to alkaline phosphatase for $30 \mathrm{~min}$. The membrane was washed twice in $0.1 \mathrm{M}$ maleic acid $(\mathrm{pH}$ 7.5), $0.15 \mathrm{M} \mathrm{NaCl}, 0.3 \%$ (v/v) Tween 20 for $20 \mathrm{~min}$ each. Then after a $5 \mathrm{~min}$ equilibration in detection buffer $(100 \mathrm{mM}$ Tris- $\mathrm{HCl} \mathrm{pH} 9.5,100 \mathrm{mM} \mathrm{NaCl})$, membrane was kept carefully on a plastic sheet and 1:100 dilution of the CSPD substrate was added on membrane dropwise around membrane edges and then covered the whole membrane by tilting it. Membrane was incubated at room temperature for $5 \mathrm{~min}$ and then placed in a plastic folder and incubated at $37^{\circ} \mathrm{C}$ for more $15 \mathrm{~min}$. Then membrane was exposed to X-ray film for $3 \mathrm{~h}$ to capture the chemiluminescent signal.

Assays for Abiotic Stress Tolerance in E. coli

Spot assay was performed to establish the function of $O s M Y B 1$ in E. coli cells. BL21 (DE3) cells were subjected to transformation with recombinant plasmid 
(pGEX4T1-MYB1) and control plasmid (pGEX4T-1). Cells were grown in LB broth till $\mathrm{OD}_{600}$ reached 0.6. Afterward, expression of recombinant protein was induced by $1 \mathrm{mM}$ IPTG and cells were incubated for further $4 \mathrm{~h}$ at $37^{\circ} \mathrm{C}$. $\mathrm{OD}_{600}$ was measured and cultures were diluted to $\mathrm{OD}_{600} 1$. Then cells were diluted to 50 -fold, 100-fold and 200-fold.

To determine salt tolerance of transformed $E$. coli cells, the diluted samples were spotted $(10 \mu \mathrm{L})$ on LB agar plates $(100 \mu \mathrm{g} / \mathrm{mL}$ ampicillin and $1.0 \mathrm{mM} \mathrm{IPTG)}$ containing 400, 500, and $600 \mathrm{mM}$ concentration gradient of $\mathrm{NaCl}$. For drought stress, LB agar plates were supplemented with $500 \mathrm{mM}, 800 \mathrm{mM}$ and $1 \mathrm{M}$ mannitol. For heat stress, $1 \mathrm{~mL}$ of each sample was kept at $50^{\circ} \mathrm{C}$ and $100 \mu \mathrm{L}$ aliquots were taken at different periods of 1,2 and $3 \mathrm{~h}$ successively. Samples were subjected to dilution by 50 -fold, 100 -fold and 200 -fold and each sample was spotted $(10 \mu \mathrm{L})$ onto LB agar plates. For cold stress, liquid cultures were placed at $-80^{\circ} \mathrm{C}$ for $24 \mathrm{~h}$. Then these cultures were allowed to thaw at $35^{\circ} \mathrm{C}$ for $1 \mathrm{~h}$ and $100 \mu \mathrm{L}$ sample was collected at time intervals of 2, 4, 6 and $8 \mathrm{~h}$ successively. Samples were diluted by 50 -fold, 100 -fold and 200-fold and $10 \mu \mathrm{L}$ of each sample was spotted onto IPTG LB agar plates. All these plates were incubated overnight at $37^{\circ} \mathrm{C}$ and photographed.

\section{RESULTS}

\section{In Silico Analysis}

The OsMYB1 cDNA (GenBank accession number XM_015775202.1) was $1560 \mathrm{bp}$ long, contained a 36 bp 5' UTR, a 1242 bp open reading frame and a 282 bp 3' UTR region. The cDNA encoded a polypeptide of 413 amino acid residues with a predicted molecular mass of $44.3 \mathrm{kDa}$ and an isoelectric point of 6.24. OSMYB1 gene was kept with AtMYB1, AtMYB25 and AtMYB109 in NCBI homologene database. Multiple sequence alignment with Arabidopsis proteins showed sequence conservation especially in DNA binding domain region (Figure 1). The secondary structure of $O s \mathrm{MYB} 1$ analyzed by PSIPRED protein structure prediction software showed that it contains 6 alpha helices in DNA binding domain region forming two helix-turn-helix motifs, and one alpha helix at the $\mathrm{C}$ terminus (Figure 2) indicating that it belongs to R2R3 type MYB family. Subcellular localization was predicted by WoLF PSORT and found to be localized in nuclei (Supplementary Figure 2)

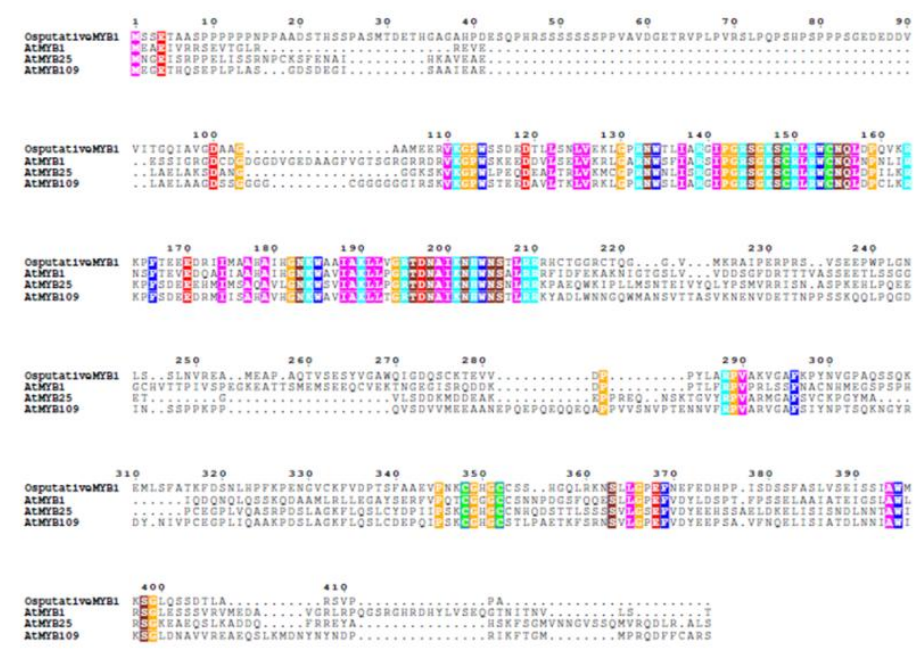

Figure 1: Protein sequence alignment of OsMYB1 with putative homologs from Arabidopsis thaliana. Conserved residues are shaded in different colors. Genbank accession numbers for AtMYB1, AtMYB25 and AtMYB109 are

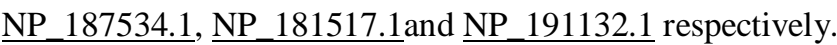




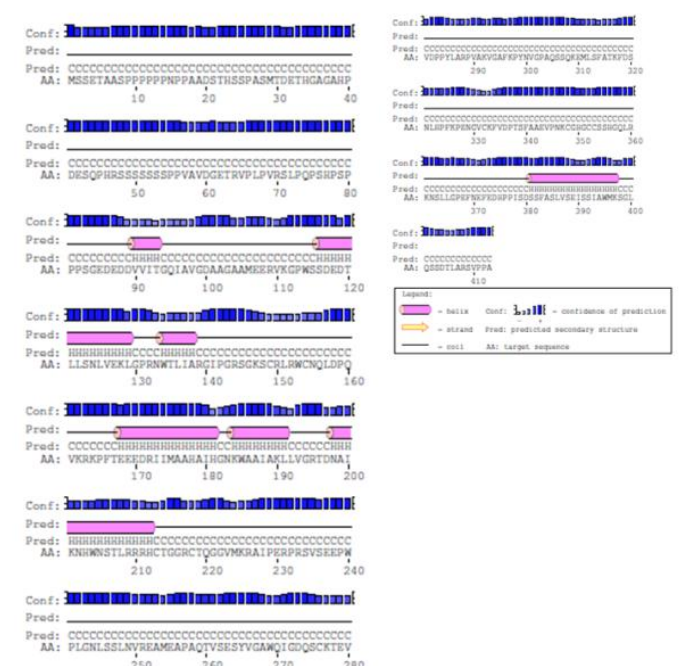

Figure 2: PSIPRED results showing secondary structures features of OsMYB1.

\section{Expression Analysis of $O$ sMYB1 by RT-qPCR}

To elucidate the role of $O s \mathrm{MYB} 1$ in plant responses to environmental stimuli, we analyzed gene expression profile in rice under various abiotic stresses using Genevestigator tools. The results indicated that the OsMYB1 expression is upregulated by some abiotic stresses, demonstrating that OsMYB1 could play significant roles in plants in response to different abiotic stresses. We then conducted RT-qPCR tests to validate the results from the Genevestigator analysis. Gene expression was examined in rice seedlings using high and low temperatures, salinity, drought and wounding. For OsMYB1, the transcript level was increased upto 23 fold upon wounding compared to control. Expression was increased ( $\sim 3$ fold) by salt, drought and heat stresses (Figure 3). These results strongly suggest that OsMYB1 gene play important roles in providing tolerance to various environmental stresses.
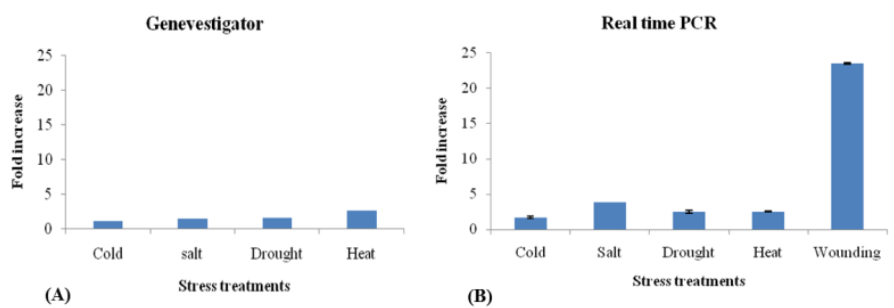

Figure 3: Expression analysis of $O s M Y B 1$ gene. A: Microarray data of $O s M Y B 1$ expression in abiotic stresses from Genevestigator . B: Relative expression of $O S M Y B 1$ in abiotic stresses by Real-time qPCR. Bars represent standard errors of the mean based on three independent experiments.

\section{Recombinant OsMYB1 protein binds to WAACCA cis-element}

To analyze the possible physical interaction of $O s$ MYB1 with WAACCA containing probe, OsMYB1 was produced as recombinant protein (GST-OsMYB1). DNA binding domain with flanking regions were cloned, fused to the GST tag in the expression vector pGEX-4T-1, expressed in BL21 and purified as GST-OsMYB1 (Supplementary Figure 3). Using the 30 bp probe containing WAACCA binding region, we used EMSA to test whether the GST/OsMYB1 protein can directly bind to the MYB-binding motif in vitro. There was no shift in both negative controls i.e labeled probe without protein and labeled probe with GST. GST-OsMYB1 bound to core sequence and a shift was observed (Figure 4). The DIG-labeled probe competed 


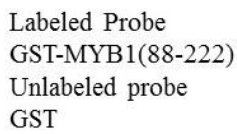

with unlabeled cold competitor probes. Protein-DNA complex was reduced by the addition of 100 and 200 fold molar excess of unlabeled competitor oligos respectively, suggesting that the signal from the probe represents the specific binding ability of the OsMYB1 with the probe. These results demonstrated that OsMYB1 was able to directly and specifically bind to the MYB-binding site in in vitro conditions.

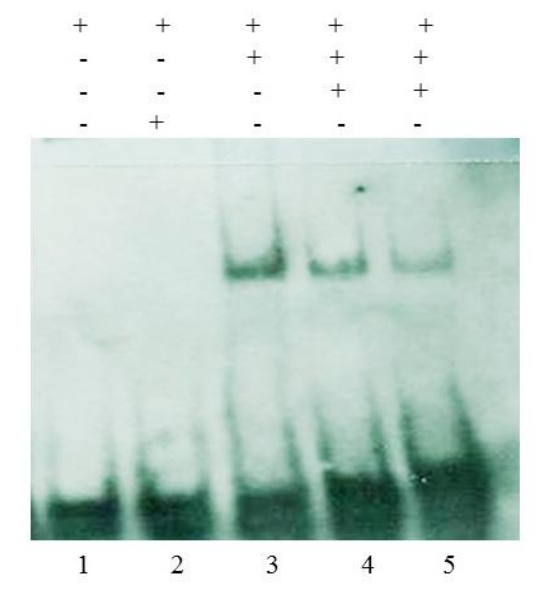

Figure 4: EMSA of recombinant $O S M Y B 1$ with a DIG-labelled probe containing WAACCA motif. Lane 1: OsMYB1 oligos negative control, Lane 2: GST negative control, Lane 3: $1 \mu \mathrm{g}$ GST-OsMYB1 with OsMYB1 oligos, Lane 4: with 100 molar excess of unlabeled OsMYB1 oligos, Lane 5: with 100 molar excess of unlabeled OsMYB1 oligos.

Expression Patterns of GST-OsMYB1 in E. coli under Different Abiotic Stresses To study the consequences of the over-expression of the OsMYBI gene on the growth of recombinant $E$. coli cells in response to various environmental stresses, cultures of BL/pGEX4T-1 and BL/OsMYB1 were diluted and spread on supplemented plates. Figure 5 showed that BL/pGEX4T-1, BL/OsMYB1 containing cells have same growth pattern on standard LB plates. However, the recombinant $E$. coli cells showed enhanced growth in comparison to control cells on plates supplemented with high salt and samples exposed to high temperature. On plates supplemented with 400 to $600 \mathrm{mM} \mathrm{NaCl}$, the survivability rate of BL/OsMYB1 cells and BL/pGEX4T-1 cells was different i.e better survival was observed for $\mathrm{BL} / O s \mathrm{MYB} 1$. There were small and few BL/OsMYB1 cells on plates supplemented with $600 \mathrm{mM} \mathrm{NaCl}$ in comparison to BL/pGEX4T-1. Furthermore, similar results were obtained with different mannitol concentrations; the colony number of $\mathrm{BL} / O s \mathrm{MYB} 1$ was more as compared to $\mathrm{BL} / \mathrm{pGEX} 4 \mathrm{~T}-1$ at high mannitol concentrations. These findings suggest that the expression of the OsMYBI gene augmented the salt and drought tolerance in $E$. coli cells. With the aim of finding the effect of over-expression of $O S M Y B 1$ gene on the growth of $E$. coli recombinants under low and high-temperature stresses, IPTG containing bacterial cultures were transferred to $-80^{\circ} \mathrm{C}$ and $50^{\circ} \mathrm{C}$ respectively. The number of cells were compared in $\mathrm{BL} / O s \mathrm{MYB} 1$ and $\mathrm{BL} / \mathrm{pGEX} 4 \mathrm{~T}-1$ plates after the temperature treatment for different time periods. Number of control cells was less as compared to BL/OsMYB1 but growth rate was stagnant for both control and BL/OsMYB1 cells after 2, 4, 6 and $8 \mathrm{~h}$ of cold treatment. Even though both cultures have less number of cells after heat shock, BL/OsMYB1 cells were more as compared to control cells. Most of the $\mathrm{BL} / \mathrm{pGEX} 4 \mathrm{~T}-1$ cells died after $3 \mathrm{~h}$ at $50^{\circ} \mathrm{C}$, while, less BL/OsMYB1 cells died at the same temperature. These outcomes indicated that the $O S M Y B 1$ gene has significantly induced tolerance to high-temperature. 


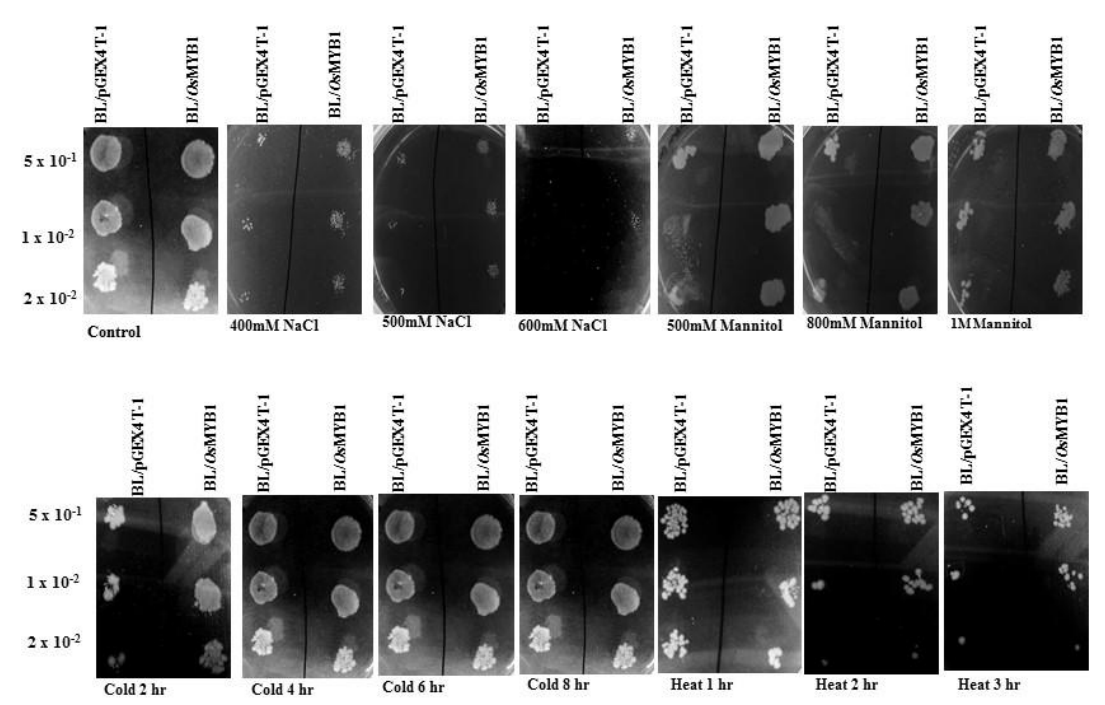

Figure 5: Spot assay of BL/pGEX4T-1 and BL/OsMYB1 recombinants. Transformed $E$. coli cells were subjected to different abiotic stresses. Induced cultures OD was adjusted to $\mathrm{OD}_{600}=1$. Then $10 \mu \mathrm{L}$ of $50-, 100-$ and 200 -fold diluted bacterial suspension was spotted on LB plates containing 400, 500 and $600 \mathrm{mM} \mathrm{NaCl}$ for salt stress; 500 , $800 \mathrm{mM}$ and $1 \mathrm{M}$ mannitol for desiccation. Samples were spotted after 2, 4, 6 and $8 \mathrm{~h}$ of cold stress and after 1, 2 and $3 \mathrm{~h}$ of heat stress.

\section{Intrinsic Disorder in OsMYB1}

Plant transcription factors belonging to different transcription factors families, such as MYB, NAC, WRKY and bZIP, have significant degrees of Intrinsic disorder regions (IDRs) which play vital role in interaction with DNA and other regulatory proteins ${ }^{12}$. DISPORED analysis predicted $60 \%$ residues to be disordered in OsMYB1. Only the DNA binding domain region is structured whereas amino acids residues surrounding the DNA binding domain are intrinsically disordered (IDs). Structure of DNA binding domain predicted by SMART contains two MYB DNA binding domains that interact with promoter region of target genes. The flanking disordered regions are supposed to be involved in DNA binding affinity and specificity. But how these disordered regions affect binding is still to be determined. DISPORED has also predicted four disordered regions involved in protein-protein interaction (Figure 6).

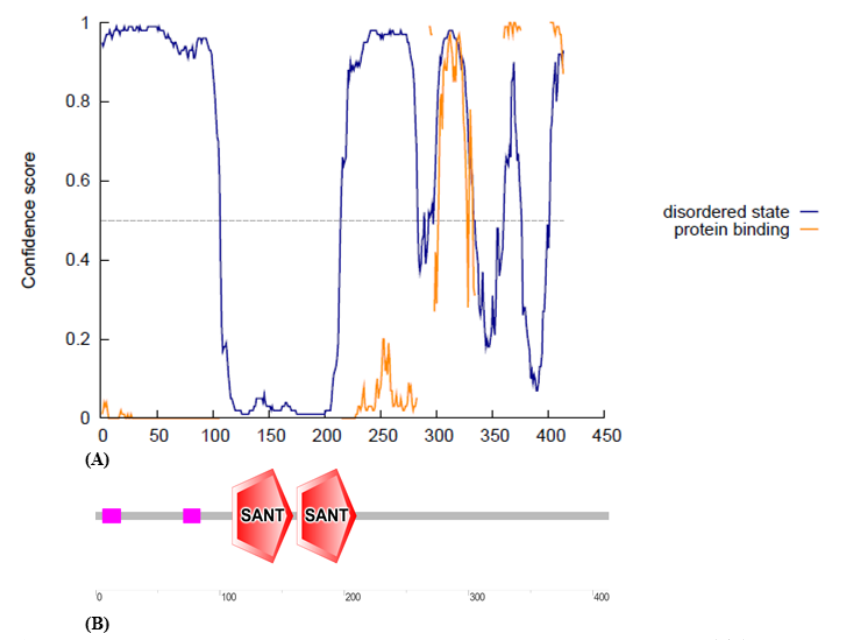

Figure 6: Intrinsic disorder (ID) prediction for OsMYB1 (A) Intrinsic disorder analysis by DISPORED. A threshold was applied with disorder assigned to values greater than or equal to 0.05 (black bar). (B) Diagrammatic representation of $O s M Y B 1$ structure. It comprises of 2 SANT DNA binding domains. 


\section{Protein-protein Interaction Analysis}

To find out how $O s \mathrm{MYB} 1$ interacts with other rice proteins and alter cell function, the protein was analyzed by searching the STRING database and the protein-protein interaction network was obtained. OsMYB1 was predicted to bind ATP-dependent RNA helicase, TAZ zinc finger proteins, DIRP family proteins and phosphoribosylamine glycine ligase with a score of 0.8-0.9. (Figure 7).
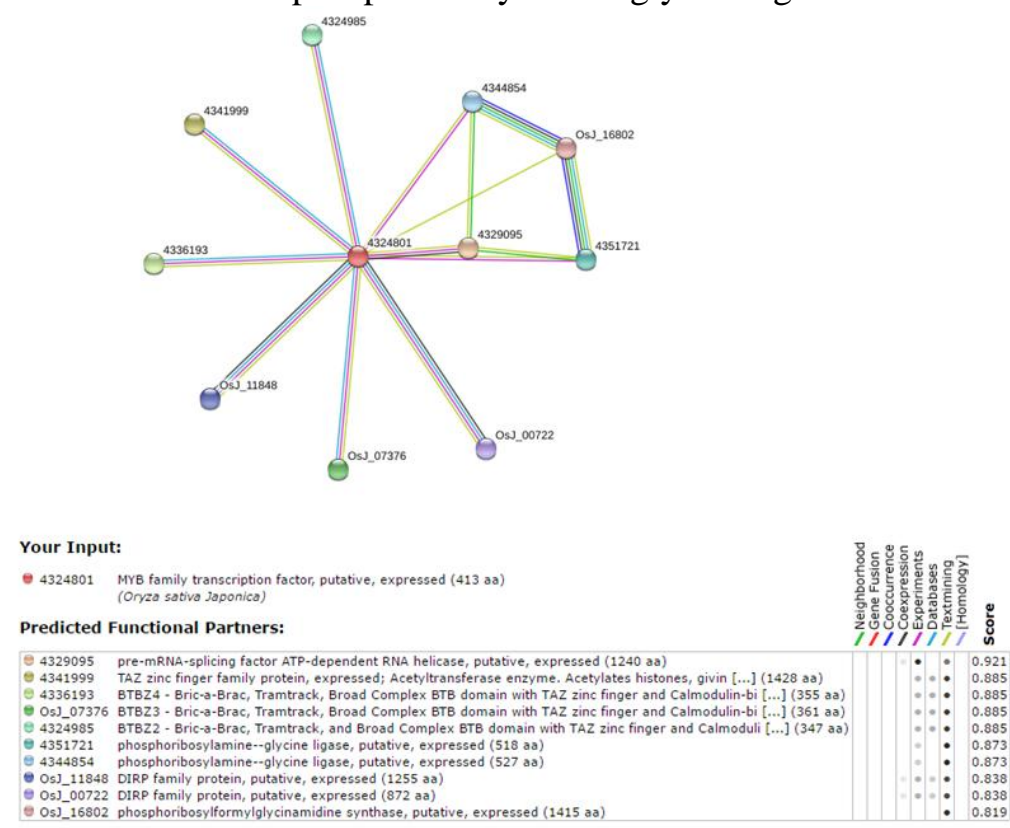

Figure 7: Protein-protein interaction network of $O s M Y B 1$ with differentially expressed proteins. In the resulting proteins network, proteins are represented by nodes which are linked by lines whose thickness tells the confidence level. Various line colors denote different kinds of associations: red line represents fusion association evidence; green line represents neighborhood association; light blue line indicates database evidence; black line represents coexpression evidence; purple line denotes experimental evidence of proteins association; yellow line represents textmining evidence and blue line indicates co-occurrence.

\section{DISCUSSION}

Transcription factors play significant roles in plant growth and development, and in responses to environmental stresses. To examine the expression of OsMYB1 gene in response to multiple abiotic stresses in rice, we took advantage of the available microarray data from GENEVESTIGATOR. To validate this expression analysis, RT-qPCR analysis was carried out. Wounding stress was also included as MYB proteins are reported to show response in wounding. The transcript level of OsMYB1 gene increased under different environmental stresses, however, their relative expression varies depending on the kind of the stress. Upon wounding stress, the expression of $O S M Y B 1$ was increased up to 23 fold compared to control, while the expression behavior for salt, drought, cold and heat stresses was same for GENEVESTIGATOR and RT-qPCR results i.e $\sim 2$ fold increase. The highest expression level of $O s \mathrm{MYB} 1$ suggests that it may have an important transcriptional regulatory role in response to wounding stress, and that the OsMYB1-mediated pathway is likely essential for responding to signals by reactive oxygen intermediates from wounding in rice. It is documented that MYB proteins interact with jasmonate signaling pathway and mediate responses to reactive oxygen species generated during wounding and biotic stresses ${ }^{13}$. For instance, AtMYB102 expression was dependent on and integrated signals from both wounding and water stress and the expression of Arabidopsis R2R3 AtMYB102 transcription factor gene 
was dependent on signals derived from both wounding and osmotic stress ${ }^{14}$. Different MYB proteins have been reported to participate in different stress response processes ${ }^{15}$. $J c$ MYB1 transcript level was reported to be up-regulated by PEG, $\mathrm{NaCl}$ and cold stresses as well as by hormones ${ }^{16}$. Katiyar et al. ${ }^{17}$ observed the upregulation of various $M Y B$ genes in rice under drought, salt and cold stresses.

It has been accounted that MYB transcription factors can recognize a specific binding motif, WAACCA and YAACKG ${ }^{18}$. An attempt was made to investigate the binding of $O s \mathrm{MYB} 1$ with a probe containing WAACCA core sequence. It was found that OsMYB1 was able to bind WAACCA cis-element. Binding was further confirmed by competitor EMSA and EMSA with mutant oligonucleotides. Specificity of interaction was confirmed by adding excess of unlabeled probes. These results suggest the involvement of OsMYB1 protein in regulating the expression of stress related genes as promoters of many stress regulated genes contain WAACCA binding motif for instance, $O s R G L P 2$ gene promoter has 4 copies of $O s \mathrm{MYB} 1$ binding motif ${ }^{19}$.

In recent times, a number of plant genes and transcription factors have been evaluated for their stress analysis using heterologous expression system of E. coli. SbsI-1, a unique salt responsive gene, from $S$. brachiata displayed drought and salinity tolerance in $E$. coli cells as investigated by Yadav et al. ${ }^{20}$. Guo et al. ${ }^{21}$ observed the drought tolerance in E.coli cells transformed with the ThPOD3 from Tamarix hispida. LEA proteins from soybean improved tolerance to E. coli cells against salt stress $^{22}$. In order to examine the function of proteins against diverse abiotic stresses, recombinant plasmid was expressed in E. coli. The differential response of $E$. coli harboring pGEX-OsMYB1 was inspected for their diverse level of tolerance to various abiotic stresses in comparison to empty pGEX-4T1 vector including salt, drought and heat stresses. Tolerance of the recombinant E. coli indicated that expression of $O s \mathrm{MYB} 1$ in host cells could confer protective function against damaging of proteins, cellular membrane, and cells and this may be a sequel to the binding of $O s \mathrm{MYB} 1$ protein to the stress-inducible promoters of the different functional genes in E. coli. There might be some common protective mechanisms in both prokaryotes and eukaryotes under stress conditions ${ }^{23}$. The MYB transcription factors are considered to be eukaryote specific and composed of helix-turn-helix domains. It is reported that eukaryotic helix-turn-helix domains are originated from prokaryotic helix-turn-helix domains ${ }^{24}$. This imitates that the regulatory system of eukaryotes and prokaryotes might have some resemblance at certain point of interaction, and related mechanisms do exist between them. Hence, it is credible to assume that $O s$ MYB1 DNA binding domain is interacting with transcriptional network in the bacterial cells and aid in stress tolerance.

In the past decade, research revealed that eukaryotic genomes contain 25 to $30 \%$ of ID proteins out of which $90 \%$ proteins are transcription factors ${ }^{25}$. Various computational methods have been employed to predict IDRs based on primary protein sequence. These IDs appear to be involved in molecular recognition, for instance, protein binding to DNA to assist transcription or replication. IDP and IDR can recognize and bind to a multiple partners at different binding sites via short regions, called Molecular Recognition Features (MoRFs) that switch from disorderto-order confirmation ${ }^{26}$. The large interaction potential permits IDRs to interact as hubs with a number of partners in interactomes ${ }^{27}$. The significance of ID for proteinprotein interactions is now being valued in plant science ${ }^{12}$. In plants, NAC transcription factors are the only class of transcription factors in which ID was studied in detail ${ }^{28}$. Our results revealed that OsMYB1 have 60\% IDRs which means that it interacts with other proteins. The protein partners were predicted by STRING. Predicted proteins partners play vital roles in photosynthesis, signal transduction, metabolism and various stress conditions. 
Role of MYB protein in abiotic stress tolerance

\section{CONCLUSION}

Taken together, it is judicious to speculate that the DNA-protein interaction mechanism for $O s \mathrm{MYB} 1$ might be alike in prokaryotes and eukaryotes in response to several environmental stresses, and it is predictable that heat, salt, drought, and wounding tolerant crops can be produced through overexpression of $O s M Y B 1$ gene.

\section{REFERENCES}

1. Matsui A, Ishida J, Morosawa T, Mochizuki Y, Kaminuma E, Endo TA, et al. Arabidopsis transcriptome analysis under drought, cold, high-salinity and ABA treatment conditions using a tiling array. Plant Cell Physiol. 2008; 49: 1135-1149.

2. Bray EA, Bailey-Serres J, Weretilnyk E. Responses to abiotic stresses. In: Gruissem W, Buchannan B, Jones R, editors. Biochemistry and Molecular Biology of Plants. American Society of Plant Physiologists, Rockville, MD; 2000. p. 1158-1249.

3. Dubos C, Stracke R, Grotewold E, Weisshaar B, Martin C, Lepiniec L. MYB transcription factors in Arabidopsis. Trends Plant Sci. 2010; 15: 573-581.

4. Klempnauer KH, Gonda TJ, Bishop JM.1982. Nucleotide sequence of the retroviral leukemia gene v-myb and its cellular progenitor c-myb: the architecture of a transduced oncogene. Cell. 1982; 31(1): 453-463.

5. Du H, Yang SS, Liang Z, Feng BR, Liu L, Huang YB, Tang YX. Genome-wide analysis of the MYB transcription factor superfamily in soybean. BMC Plant Biol. 2012; 12(1): 1.

6. Zhu Y, Dong C, Zhu JK, Hasegawa PM, Bressan RA. HOS10 encodes an R2R3-type MYB transcription factor essential for cold acclimation in plants. Proc Natl Acad Sci USA. 2005; 12: 9966-9971.

7. Gao Z, Liu C, Zhang Y, Li Y, Yi K, Zhao X, Cui ML. The promoter structure differentiation of a MYB transcription factor RLC1 causes red leaf coloration in empire red leaf cotton under light. PloS one. 2013; 8(10): 1-12.

8. Denekamp M, Smeekens SC. Integration of wounding and osmotic stress signals determines the expression of the AtMYB102 transcription factor gene. Plant Physiol. 2003; 132(3): 1415-1423.

9. Seo PJ, Xiang F, Qiao M, Park JY, Lee YN et al. The MYB96 transcription factor mediates abscisic acid signaling during drought stress response in Arabidopsis. Plant Physiol. 2009; 151: 275-289.

10. El-Kereamy A, Bi YM, Ranathunge K, Beatty PH, Good AG, et al. The rice R2R3-MYB transcription factor $O s \mathrm{MYB} 55$ is involved in the tolerance to high temperature and modulates amino acid metabolism. PLoS One. 2012; 7: 1-16.

11. Yang A, Dai X, Zhang WH. A R2R3-type MYB gene, OsMYB2, is involved in salt, cold, and dehydration tolerance in rice. J Exp Bot. 2012; 63: 2541-2556.

12. Kragelund BB, Jensen MK, Skriver K. Order by disorder in plant signaling. Trends Plant Sci. 2012; 17: 625-632.

13. Mengiste T, Chen X, Salmeron J, Dietrich R. The BOTRYTIS SUSCEPTIBLE1 gene encodes an R2R3MYB transcription factor protein that is required for biotic and abiotic stress responses inArabidopsis. Plant Cell. 2003;15:2551-2565.

14. Denekamp M, Smeekens SC. Integration of wounding and osmotic stress signals determines the expression of the AtMYB102 transcription factor gene. Plant Physiol. 2003;132:1415-1423.

15. Cheng L, Li X, Huang X, Ma T, Liang Y, Ma X, et al. Over-expression of sheep grass R1-MYB transcription factor LcMYB 1 confers salt tolerance in transgenic Arabidopsis. Plant Physiol Biochem. 2013; 70(1): 252-260.

16. Liang $\mathrm{G}, \mathrm{He} \mathrm{H}, \mathrm{Li} \mathrm{Y}, \mathrm{Ai}$ Q, Yu D. MYB82 functions in regulation of trichome development in Arabidopsis. J Exp Bot. 2014; 65(12): 3215-3223.

17. Katiyar A, Smita S, Lenka SK, Rajwanshi R, Chinnusamy V, Bansal KC. Genome-wide classification and expression analysis of MYB transcription factor families in rice and Arabidopsis. BMC Genomics. 2012; 10(1): 544-556. 
18. Abe H, Urao T, Ito T, Seki M, Shinozaki K, Yamaguchi-Shinozaki K. Arabidopsis AtMYC2 (bHLH) and AtMYB2 (MYB) function as transcriptional activators in abscisic acid signaling. Plant Cell. 2003; 15(1): 63-78.

19. Mahmood T, Hyder MZ, Naqvi SMS. Cloning and sequence analysis of germin-like protein gene 2 promoter from Oryza sativa L. ssp. Indica. DNA Seq. 2007; 18(1): 26-32.

20. Yadav NS, Rashmi D, Singh D, Agarwal PK, Jha B. A novel salt-inducible gene SbSI-I from Salicornia brachiata confers salt and desiccation tolerance in E. coli. Mol Biol Rep. 2012; 39(2): 1943-1948.

21. Guo X-H, Jiang J, Wang B-C, Li H-Y, Wang Y-C, Yang C-P, Liu G-F. ThPOD3, a truncated polypeptide from Tamarix hispida, conferred drought tolerance in Escherichia coli. Mol Biol Rep. 2010; 37(3): 1183-1190.

22. Lan Y, Cai D, Zheng Y. Expression in Escherichia coli of three different soybean late embryogenesis abundant (LEA) genes to investigate enhanced stress tolerance. J Integr Plant Biol. 2005; 47(5): 613-621.

23. Liu Y, Zheng Y. PM2, a group 3 LEA protein from soybean, and its 22-mer repeating region confer salt tolerance in Escherichia coli. Biochem Biophys Res Commun. 2005; 331:325-332.

24. Aravind L, Anantharaman V, Balaji S, Babu MM, Iyer LM. The many faces of the helixturn-helix domain: transcription regulation and beyond. FEMS Microbial Rev. 2005; 29(2): 231-262.

25. Liu J, Perumal NB, Oldfield CJ, Su EW, Uversky VN, Dunker AK. Intrinsic Disorder in transcription factors. Biochemistry. 2006; 45: 6873-6888.

26. Uversky VN. Intrinsically disordered proteins from A to Z. Int J Biochem Cell Biol. 2011; 43: 1090-1103.

27. Han JD, Bertin N, Hao T, Goldberg DS, Berriz GF, Zhang LV, et al. Evidence for dynamically organized modularity in the yeast protein-protein interaction network. Nature. 2004; 430: 88-93.

28. Jensen MK, Kjaersgaard T, Nielsen MM, Galberg P, Petersen K, O'Shea C, Skriver K. The Arabidopsis thaliana NAC transcription factor family: structure-function relationships and determinants of ANAC019 stress signaling. Biochem J. 2010; 426: 183-196. 